\title{
A Personal Reflection on the Key Challenge for Higher Education: Improving the Quality of University Instruction
}

\author{
David Dill
}

\section{Introduction}

Since the founding of the University of Bologna in 1088, the quality and societal impact of university-based research has steadily risen and is widely expected to continually improve in the future. But, while the effectiveness of university teaching over this same period has improved through the adoption of laboratory instruction, the seminar method, tutorials, and more valid and reliable means of assessing students, the qualitative enhancement and continuous development of instruction compared to research appears less certain. Why does this difference exist? I will argue the cause is to be found in the limitations of universities' traditional collegial culture and in the failure of recent national efforts to improve academic quality to effectively address academic norms and values.

Detailed sociological studies of leading universities (Paradeise and Thoenig 2015) have confirmed the influential role professional norms and a shared academic culture play in motivating and assuring the continual improvement of academic research. In these elite universities, communal norms generated and communicated through the social interactions occurring within and between academic subunits and among academic staff are the primary means of collegial control over the quality of university research. These interactions include many formal and informal internal conversations among academic staff as well as repeated self- and cross- evaluations, which strongly regulate the research behaviour of faculty members in differentiated academic units. But, while this academic culture is influential on the research behaviour of academic staff, the university context for instruction and student learning is more frequently reflective of "hollowed collegiality" (Massy et al. 1994). That is, while faculties meet collectively to discuss what particular courses should be offered and who should teach them, active collegial efforts to improve curricular structure, pedagogical alternatives,

D. Dill ( $\varangle)$

The University of North Carolina at Chapel Hill, NC, USA

e-mail: david_dill@unc.edu 
and student assessment are often avoided because of the commitment of individual staff members to the values of individual autonomy and academic freedom.

How do we create incentives for cooperative behaviour to improve student learning in an institution that is organised to encourage individual discretion in teaching and research? What is most needed, in my view, is the effective implementation within universities of a collegial process of science-based peer review of instruction and student assessment.

\section{A Framework for Effective Collegial Control}

Lazega (2005) has developed and empirically tested a sociological model of the social processes indispensable for effective professional behaviour in knowledge-based, collegial organisations. Lazega focuses on the mechanisms which make it possible for interconnected professionals to cooperate and engage in collective actions for the efficient production of complex work. These include "essential values and norms," "authority to know," "lateral control mechanisms," "graduated sanctions," and "precarious professional values". His model offers potentially valuable concepts for the design of effective means of continually improving and assuring instructional quality in collegially governed universities.

A first issue is whether university policies effectively define and communicate "essential values and norms," the professional values and ethical obligations indispensable to effective instruction and student assessment. Some national quality assurance agencies have attempted to address professional values and norms regarding teaching and student learning (Daniel 2016). At the institutional level, a leading example is the Principles of Teaching and Learning (Eberly center 2017) developed and communicated to its faculty by Carnegie Mellon University (CMU) in the US. These principles were derived from the rigorous and respected research on effective university course design conducted by the Open Learning Institute at CMU.

The second issue is whether a university possesses an effective "lateral control mechanism," a horizontal process for monitoring and enforcing the professional norms essential to achieving effective instruction and student learning. Because teaching and student assessment practices often vary across departments and degree programs within the same university, peer review of a programme's methods is more beneficial if it is truly cross-disciplinary, or as Lazega has suggested, horizontal. This is the most effective means for assuring academic standards within a university as well as for promoting the transfer of effective tools for improving instructional quality and student learning among academic programmes. A comparable collegial control mechanism, termed "academic quality work," has been designed and implemented in Hong Kong universities as well as in the US public university systems of Missouri and Tennessee (Massy et al. 2007).

A third issue is "who should be awarded the authority to know" in evaluating university instruction and student assessment? Many universities now rely on standardised student surveys of university teaching, but studies in both the US and France 
(Stark and Freishtat 2014; Boring et al. 2016) have discovered these surveys to be biased by discriminatory evaluations of women and minorities, positively associated with the award of inflated student grades, and negatively related to direct evidence of student learning. To better monitor and improve instruction, direct assessments of teaching behaviour appear more valid, such as systematic appraisals of instructional materials and classroom observations by academic peers, evaluation methods much less commonly employed within universities.

In addition, accumulating research in the field of "learning science" (Massy 2016) is now making significant contributions to our understanding of how effective learning at university level takes place and the means by which instruction and student assessment can be improved for maximum effectiveness. Potentially effective assessment of instructional quality and student assessment should therefore include rigorous evaluation of whether an entity - a university, an academic programme, or a course module within a university - reflects the principles and values emerging from research on learning science. But, unlike peer reviews in research, there appears to be no similar expectation in the US or other nations that external review teams assessing universities or internal university committees evaluating instructional quality are staffed by researchers with the scientific expertise to thoroughly evaluate the validity, reliability, and efficiency of methods of instruction, student marking and assessment.

A fourth issue is the use of "graduated sanctions" for controlling unprofessional or opportunistic academic behaviour. Direct command or the use of administrative hierarchy are inappropriate means for exercising control in universities because of the complexity of academic tasks and the need for individual autonomy. Consequently, effective collegial organisations apply personalised means of professional monitoring and sanctioning by individuals respected by their colleagues in order to maintain future relationships. Therefore, graduated sanctions for university teaching would start as already noted with a clear communication of normative expectations for instruction and student assessment, followed by discussion and counsel with relevant programmes on means of improving discovered flawed practices. Only after thoughtful and systematic efforts at personal guidance and education have been conducted might a negative action on an instructional quality decision be rendered.

The most effective example of this process I have observed was at a world class university in Hong Kong where an elected Faculty Senate Committee on Teaching and Learning Quality reviewed annual reports from each academic programme on its processes for assuring effective teaching, student learning, and marking standards. The committee included a number of the university's most distinguished professors. When the committee had questions about the rigour or effectiveness of a programme's processes, they met in person with the programme's collective faculty to discuss needed changes and improvements and then followed up systematically on proposed reforms. One may question the influence of such cross-disciplinary discussions of teaching and student learning, but research on collegial organisations (Ostrom and Walker 1997) emphasises that face to face communication is the most effective means of producing substantial increases in needed cooperation and coordination over time. Furthermore, field studies (Hage 1974) have confirmed that communication influential on individual professional behaviour is not vertical as from administrators, 
nor primarily written as in reports or procedural documents, nor episodic. Rather, communication helpful to professional practice is horizontal, with respected peers, largely verbal and face-to-face, continuous, and focused on the exchange of information about the means of improving core professional tasks.

Finally, contemporary collegial organisations grappling with changing technology also need collective means for renegotiating "precarious professional values" such as the concept of academic freedom. The implementation in universities of a "lateral control mechanism" such as a multi-disciplinary academic quality assurance committee has often been resisted by academics advocating individual autonomy regarding means of instruction and student marking. But, as contemporary universities have grappled with ethical lapses of academic staff in both research and instruction, it is increasingly apparent the independence of thought necessary to advance knowledge and properly educate students is linked to professional responsibilities, "which include the obligation to adhere to professional norms and to discipline those who fail to do so" (Bowen and Tobin 2015, 201).

How feasible would it be to induce university faculties to adopt the needed core values and supporting collegial mechanisms to effectively evaluate and continually improve instruction and student assessment in universities? Ironically, over the last several decades, as a number of countries have implemented academic quality assurance policies with mixed success, a parallel effort to assure ethical practices in university research on human subjects in the US and a number of developed countries has proved much more influential. What distinguishes the US approach to university quality assurance from its approach to university research on human subjects is the latter policy has adopted a design more reflective of Lazega's principles for effective collegial governance (Dill 2020). For example, the US policy began by articulating the essential professional values for relevant research conduct and required that each university develop means for effectively communicating these ethical obligations to all relevant staff. The policy also required each university to implement a peer-based mechanism for the review of all relevant proposals for human subjects research and designated the type of scientific expertise each review team would need to include in its review. Finally, applications for federally-funded proposals for academic research were contingent on effective university implementation and continuous improvement of these professional values and controls.

\section{Conclusion}

A major challenge for higher education will be identifying how the academic community itself can act to restore and develop the internal web of collegial accountability whereby the quality of instruction, student learning, and assessment can be continually assured and improved. Responsibility for the effectiveness of teaching and learning must remain where the power exists to control or change academic practices-with the faculty of an institution. Seeking means to better understand 
and to strengthen the processes within universities whilst ensuring that the faculty collectively and within academic units can successfully exercise its responsibility for instructional quality assurance and improvement appears to be a critical goal.

\section{References}

Boring, A., Ottoboni, K., \& Stark, P. B. (2016). Teaching evaluations (mostly) do not measure teaching effectiveness. Science Open. https://doi.org/10.14293/S2199-1006.1.SOR-EDU.AETBZC. v1.

Bowen, W. G., \& Tobin, E. M. (2015). Locus of authority: The evolution of faculty roles in the governance of higher education. Princeton: Princeton University Press.

Eberly Center for Teaching Excellence and Educational Innovation (2017). Principles of teaching and learning. Retrieved from: www.cmu.edu/teaching/principles/ (9.07.2020)

Daniel, J. (2016). Advisory statement for effective international practice: Combatting corruption and enhancing integrity: A contemporary challenge for the quality and credibility of higher education. Council for Higher Education Accreditation, Retrieved from: https://files.eric.ed.gov/ fulltext/ED603202.pdf. (9.07.2020)

Dill, D. D. (2020). Enhancing academic quality and collegial control: Insights from US policy on the ethical conduct of human subjects' research. Higher Education Policy, 33(1), 45-64.

Hage, J. (1974). Communication and organizational control: Cybernetics in health and welfare settings. New York: John Wiley.

Lazega E. (2005). The theory of collegiality and its relevance for understanding professions and knowledge intensive organizations. In T. Klatetzki \& V. Tacke (Eds.), Organisation und Profession (pp. 221-251). Wiesbaden: Verlag für Sozialwissenschaften. pp. 221-251.

Massy, W. F. (2016). Reengineering the university. Baltimore: Johns Hopkins University Press.

Massy, W. F., Graham, S. W., \& Short, P. M. (2007). Academic quality work: A handbook for improvement. San Francisco: Jossey-Bass.

Massy, W. F., Wilger, A. K., \& Colbeck, C. (1994). Overcoming hollowed collegiality. Change, 26(4): 10-20.

Ostrom, E. \& Walker, J. (1997). Neither markets nor states: Linking transformation processes in collective action arenas. In D. C. Mueller (Ed.), Perspectives on public choice: A handbook. Cambridge: Cambridge University Press.

Paradeise, C. \& Thoenig, J.-C. (2015) In search of academic quality. New York: Palgrave Macmillan. Stark, P. B. \& Freishtat, R. (2014). An evaluation of course valuations. Science Open.; 1.SOREDU.AOFRQA.v1, https://doi.org/10.14293/S2199-1006.

David Dill is professor emeritus of Public Policy at The University of North Carolina-Chapel Hill. He has published extensively on higher education policy, research policy, and the governance and management of higher education. His work was recognized with election as a Life Fellow of the Society for Research into Higher Education (SRHE) in the UK. With the support of the Ford Foundation, David Dill created the Research Program on Public Policy for Academic Quality, a cross-national study of quality assurance policies in higher education. 
Open Access This chapter is licensed under the terms of the Creative Commons Attribution 4.0 International License (http://creativecommons.org/licenses/by/4.0/), which permits use, sharing, adaptation, distribution and reproduction in any medium or format, as long as you give appropriate credit to the original author(s) and the source, provide a link to the Creative Commons license and indicate if changes were made.

The images or other third party material in this chapter are included in the chapter's Creative Commons license, unless indicated otherwise in a credit line to the material. If material is not included in the chapter's Creative Commons license and your intended use is not permitted by statutory regulation or exceeds the permitted use, you will need to obtain permission directly from the copyright holder. 